\title{
Impact of Infrastructure and Institutional Quality on Industrial Sector of Pakistan
}

\author{
Shehnaz ${ }^{* 1}$, Tayyaba Idrees ${ }^{2}$, \& Kaleem Anwar Mir ${ }^{3}$ \\ 1 ,2Fatima Jinnah women university Rawalpindi, Pakistan \\ ${ }^{3}$ Global Change Impact Studies Centre, Ministry of Climate Change, Islamabad, Pakistan
}

\begin{abstract}
The purpose of this study is to analyze the impact of infrastructure and institutional quality on industrial growth of Pakistan. The study covers the time span of 1984 2012. The ARDL (Auto Regressive Distributive Lag) is employed to see the combine and individual impact of infrastructure and institutional quality on industrial growth of Pakistan, respectively. Both infrastructure and institutional quality are measured through two distinct proxies. Infrastructure and institutional quality are found to be positively related to industrial growth. Based on the results of present study it is beneficial to make the institutions strong and invest more on infrastructure development.
\end{abstract}

\section{Introduction}

Infrastructure can be a vector of change in addressing some of the most systemic development challenges of today's world: social stability, rapid urbanization, climate change adaptation, mitigation and natural disasters. Without an infrastructure that supports green and inclusive growth, countries will not only find it harder to meet unmet basic needs, they will struggle to improve competitiveness. Today, the infrastructure gap in low and middle-income countries is estimated at US $\$ 1$ trillion. More and more, countries need to turn to the private sector as well as the public sector to build and operate their essential infrastructure.

Society comprises of different individuals, their goal is not only to maximize individual's welfare but of society as a whole. Welfare level can be calculated through analyzing quality of life an individual possess Aschauer (1990). Aspirations of economic development are major reason behind the expansion of infrastructure, as it ensures better quality of life. Without an infrastructure that scales up growth, countries will find it harder to meet unmet basic needs. Apart from that, they struggle to improve competitiveness Aschauer (1988). Providing infrastructure without the sound institutional framework will pose a threat to sustainable economic growth. Institutions are made by government, to shape the incentives for key economic actors of the society. Economies facing institutional bottlenecks fail to compete as in all its forms and shapes, it assists in shaping the performances of economic agents to attain sustainable economic growth; while the avail-

\footnotetext{
${ }^{1}$ Corresponding author.

Email: shehnaz@gmail.com
}

ability of infrastructure speeds up specialization process. In contemporary times, the institutional deficiencies and loopholes are the main reasons behind less growth promoting investments. To accelerate growth, overall or sectoral, the imperative need is to provide access to markets. Hence, both institutional quality and infrastructure have significant impact on industrial growth (Valeriani et al., 2011).

Many studies have been conducted in order to analyze the linear relationship between infrastructure and institutional quality (Esfahani and Ramirez, 2003; Mamatzakis, 1999; Okoh and Ebi, 2013). Whereas, the perspective of combine impact of infrastructure and institutional quality on industrial growth is yet unexplored. Since last two decades, Pakistan has been facing the deteriorating conditions of infrastructure. Imran and Niazi (2011) called the low quality of infrastructure a hindrance in achieving the sustainable growth of production sector in Pakistan. This low industrial growth slowed down the economic growth of Pakistan (Power, 1963). There is a set of theorists, who affirmed the role of institutions in shaping the pattern of economic development. They grounded and based their analysis on the development of industrial sector (Seidman, 1994). Since institutions play pivotal role in paving or restraining the way of economic growth; they may help the economy in fostering growth or prove to be a friction in the implementation of industrial policies. Keeping in view the importance of institutions and infrastructure, the present study will evaluate their combined impact on industrial growth. The hypothesis of the study is "The combined effect of infrastructure and in- 
stitutional quality on industrial growth is positive."

Present study adapted the framework of Okoh and Ebi (2013) to evaluate the long run combined impact of institutional quality and infrastructure on industrial growth of Pakistan. Based on the findings, few policy recommendations are stated.

The rest of the study is organized as follows. Section 2 makes a comprehensive theoretical and empirical appraisal of the existing literature. Section 3 contains the data description and methodology that explains the estimation technique. Section 4 presents the results and discussion while section 5 concludes the study.

\section{Literature Review}

Following section contains comprehensive theoretical and empirical appraisal of the existing literature; to analyze the impact infrastructure and institutional quality on industrial growth of Pakistan.

\subsection{Infrastructure and Industrial Growth}

The individual, as well as combined effect of infrastructure investment and institutional quality on economic growth, were examined by Okoh and Ebi (2013). The study ultimately presents three results. Increase in infrastructure investment is found to have positive relation with economic growth. Lower institutional quality renders economic growth. While, the combined effect of infrastructure investment and institutional quality on economic growth was nonsignificant. The above mentioned study makes it clear that the positive affect of infrastructure investment is dependent on institutional quality. The individual impact of infrastructure and institution on growth are examined in many studies, including Rodrik et al. (2004) and Chong and Calderon (2000).

Esfahani and Ramirez (2003) contributed in literature by evaluating contribution of institutions and infrastructure to GDPin a cross-country analysis. The study employed simultaneous equation model to avoid simultaneity problem. The study incorporates data of 75 countries for the time-period of 1965-1995. Telephone lines were used as proxy for infrastructure. The results showed that the contribution of infrastructure to GDP is substantial and the contribution overweighs the cost of provision of these services. The results suggest, apart from other factors, infrastructure is important for development. Mamatzakis (1999) while examining the impact of public infrastructure on Greek manufacturing sectors, finds out that improvement in infrastructure reduce the cost of production hence positive impact on productivity. It is clear from the study that cost elasticity is negative with respect to public infrastructure for most of the industries ${ }^{1}$. When investment in public infrastructure increases, the cost of production reduces; results in the increased efficiency and growth of industrial sector of Pakistan. There exist the evidences of both negative and positive relationship between infrastructure and industrial growth rate. Shah (1992) conducted a study for 26 Mexican manufacturing industries over the time span of 1970-1987. Gauss-Newton's method is used to evaluate the impact of investment in public sector infrastructure on performance of industrial sector. They imposed price homogeneity condition, which led to system of equation nonlinear in parameters. Therefore, an estimation technique, which is useful to remove heteroskedasticity, is employed. The reported study found out that public infrastructure is having very small and positive impact on industrial profitability. They also found that private sector responded more positively to direct/voluntary investment in public infrastructure as compared to involuntary/ indirect investment.

Démurger (2001) analyzed the relationship of infrastructure and growth for China. The researcher analyzed 24 provinces of China for the period of 19851998. According to development strategies, investment should be made considering the importance of that particular sector. From year 1960 onwards, there was emphasis on heavy industry development and provisional self-sufficiency since infrastructure improvement played pivotal role in market development; therefore, making it imperative to determine that underdeveloped infrastructure networks lead to growing regional disequilibrium in China. Simple growth model revealed different geographical location, infrastructure investment, and telecommunication facilities matter a lot for better performance of provinces.

Arnold et al. (2015) examined Indian manufacturing growth for the time span of 1993-2005 by using time series model. This study employed Ordinary Least Square (OLS) to test Cobb Douglas Production function. The study analyzed both policy changes and its implementations. Along with finding positive relationship between private sector participation and services in manufacture sector, the study found, development of infrastructure led to industrial growth. However, they analyzed just the impact of infrastructure on industrial growth regardless of institutions.

\subsection{Institutions and Industrial Growth}

Meyer and Sinani (2009) argued that institutional framework creates incentives and business practices, which in turn affect the nature of competition. Both foreign and domestic firms are encouraged to compete

\footnotetext{
${ }^{1}$ Cost of production has negative relation with availability of infrastructure. Investment in public infrastructure facilitates industrial transactions. Therefore, investment in public infrastructure will reduce cost of production in industries
} 
in an environment protected by market rules. Heckelman and Powell (2008) contributed to the existing literature presented previously by Leff (1964) and Huntington (1968). Leff (1964) and Huntington (1968) believed that corruption has positive impact on economic growth. They state that government's failure to implement pure and good rules provoke corruption, which in turn help economies to grow. However, Nawatmi et al. (2016) empirically tested this hypothesis. The reported study analyzed the relationship for 83 countries. Countries were categorized based on their economic freedom. Democracy is associated with the overall economic freedom index. Using independent variables including log initial GDP, investment, democracy, corruption, and a set of regional dummies. Following the footsteps of Clarke (1995) and Fölster and Henrekson (1999) this study employed Weighted Least Square (stocktickerWLS) to steer clear of the issue of heteroscedasticity. This study gave the results that benefit of corruption for growth increases with increasing level of democracy. Therefore, conclusion of the study is that positive or negative impacts of corruption depend on quality of institutions. The study suggested that when government fails to operate under laws and regulation, then corruption is the best way to increase growth.

While examining the impact of institution quality on industrial growth Grigorian and Martinez (1999) hypothesized that the marginal effect of institutional improvements on industrial growth will be stronger in transition economies. Redek and Sušjan (2005) tested this hypothesis later on and concluded there exists a strong negative relation between institutions and economic growth, in case of transitional economies. The institutional theory, recommended by North (1993) suggests that institutions set market rules, ensure interactions among economic actors confirmed that economic actions are binded by these rules.

\section{Data and Model Specification}

For empirical investigation of macro-economic variables, the data have been retrieved from secondary sources. The present study retrieved data from World Development Indicator (WDI), International Country Risk Guide (ICRG), and Economic Survey of Pakistan. The time series data are employed over time span of 1984- 2012. Non-availability of data for corruption, limits the timeperiod to 28 years.

However, length of roads and telephone lines are used as proxies for infrastructure. Length of roads and telephone lines were previously used as proxy for infrastructure by Loayza and Wada (2012). Data for length of roads are retrieved from Economic Survey of Pakistan; whereas, the data for telephone lines are retrieved from World Development Indicator (WDI).

To analyze impact of institutional quality on industrial sector of Pakistan, two proxies are used in the present study. First, Corruption and second is Contract Intensive Money Index (CIM). Previously these two indicators were used as proxy for institutional quality by Bassey et al. (2013), for Nigeria. Data for corruption are retrieved from International Country Risk Guide (ICRG). Contract intensive money index is calculated through following formula. The calculation of CIM is based on mathematical formula provided by Okoh and Ebi (2013).

$$
C I M=\frac{M_{2}-C_{0}}{M_{2}}
$$

While,

$$
\begin{aligned}
& M_{2}=\text { money and quasi money } \\
& C_{0}=\text { currency in circulation }
\end{aligned}
$$

The study used CIM as proxy of institutional quality that measures or gauges the enforceability and security of property rights.

Other than institutional quality and infrastructure, some other variables, which determine industrial growth, are added to avoid specification bias. Present study used trade openness, gross capital formation, real effective exchange rate and the variable of financial development as determinants of industrial sector ${ }^{2}$.

\subsection{Model and Methodology}

In order to empirically investigate the short and long run impact of infrastructure and institutional quality on the growth of industrial sector of Pakistan, present study employed Auto-Regressive Distributed Lag (ARDL) bound testing approach. It is proposed by Pesaran et al. (2001).

ARDL has an edge over other estimation techniques as it does not only provide estimates of short and long run components of the simultaneous model but it also removes the problems of exclusion bias and autocorrelation (Narayan, 2004).

Prior to all estimation unit root test will be applied, to determine the stationarity of the variables. The estimation started with conducting the bound test for the null hypothesis of no co-integration. The rejection and acceptance of null hypothesis was decided based on the value of F statistic described by (Pesaran et al., 2001)

\footnotetext{
${ }^{2}$ proxied as the money and quasi money

${ }^{3}$ If the F-statistics will be higher than the upper critical value, the null hypothesis of no long-run relationship will be rejected regardless of whether the underplaying order of integration of the variables is zero or one.
} 
${ }^{3}$. Following that criteria the estimation proceeded towards short run and long run estimations.

Estimation will be preceded using proxies for infrastructure and institutional growth as follow.

$$
\begin{aligned}
& I G_{t}=I N F_{t}+I N F_{t}^{2}+G C F_{t}+ \\
& T O_{t}+L R E E R_{t}+F D_{t}+\mu_{t} \quad \ldots \mathrm{A} \\
& I G_{t}=I N F_{t}+I N F_{t}^{2}+G C F_{t}+T O_{t} \ldots \mathrm{B} \\
& +L R E E R_{t}+F D_{t}+I N S T_{t}+\mu_{t}
\end{aligned}
$$

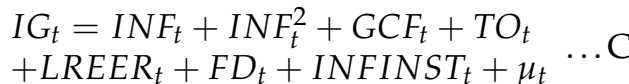

Whereas;

\section{' $t$ ' denotes the time period}

IG = Industrial growth

INF $=$ Infrastructure (Length of Roads and Telephone Lines)

INST = Institutional quality (Corruption and CIM)

$\mathrm{TO}=$ Trade openness

FD $=$ Financial Development (money and qusai money)

$\mathrm{GCF}=$ Gross capital formation $(\%$ of GDP)

REER= Real Effective Exchange Rate

$\mu_{1}=$ Error terms

After estimation of long run results, CUSUM (cumulative sum) test will be applied to check the stability of the model. To check the heteroskedasticity, BreuschPagan-Godfrey Test will be applied. Depending on probability value of BG test, the presence or absence of heteroscedasticity will be determined. To check normality of data, JarqueBera test will be applied. Probability value of JB test is expected to be higher than $10 \%$ so, null hypothesis of no skewness will be accepted.

\section{Results and Discussions}

Prior to analysis, the study investigates the order of integration for each variable included in estimation, through Augmented Dickey Fuller (ADF) test ${ }^{4}$. Results showed that there exists the (Pesaran et al., 2001) criteria $^{5}$. Therefore, the estimation can be proceede further. The second step for ARDL approach is to find appropriate lag length depending on which short run and long run relationship among the variables will be checked. In the next step the bound test is applied on each equation of the four models, with two proxies of infrastructure and institutional quality (refer to table 4.1)

\subsection{Diagnostic Tests}

Prior to long run results some diagnostic tests were applied (results given in Table 4.2 bellow). Serial correlation LM test is applied to check the correlation of variables with its past values. Breusch-Pagan-Godfrey test is applied to check the heteroscedasticity of the data. Stability of the model is assured by CUSUM (cumulative sum test), CUSUM square test and histogram normality test is applied ascertain that the normality assumptions are satisfied. In reference to table 4.4, depending on the p-value the null hypothesis of no hetero is accepted. It means that the data is homoscedastic. Histogram normality test shows that normality assumptions are truly satisfied. The null hypothesis of no skew in the data is accepted.

CUSUM recursive residual test and CUSUM square test are applied to check the stability of the model. It is clear that both the models are stable at $5 \%$ significance.

\subsection{Results of Long Run}

The results show that all the variables are significantly effecting industrial growth except contract intensive money index and trade openness.

In reference to Table 4.3, Length of roads is positively associated with industrial growth and it has a significant impact on industrial growth of Pakistan. It is estimated that $1 \%$ increase in length of roads will improve the industrial growth by $11 \%$. In the next equation, a proxy for institutional quality (corruption) is added. It is shown that in presence of corruption, $1 \%$ increase in length of roads will increase industrial growth by $5 \%$. Comparing the results with the previous equation, it is clear that the impact of change in length of roads is less. The industrial growth of Pakistan is associated negatively to quality of institutions. According to corruption index, provided by Thompson and Shah (2005), the higher value of corruption index refers to clean institutions. Hence, the results can be interpreted as 1 unit increase in corruption will increase the industrial growth by $0.04 \%$. In the next step, the estimation was carried with CIM. . The results show that CIM is associated positively with industrial growth. While, the coefficient of length of roads can be interpreted as, in presence of low contract enforceability, $1 \%$ change in length of roads will increase the industrial growth by almost 15\%. Furthermore, the result shows that the coefficient of combine impact of

\footnotetext{
${ }^{4}$ For results check appendix

${ }^{5}$ co-integration level of all variables must be a combination of level and first difference
} 
Table 4.1:

\begin{tabular}{lcccc}
\hline Equation & f-statistics & Significance & \multicolumn{2}{c}{ Critical bounds } \\
\hline Lrds & & & 0 bound & 1 bound \\
Lrds + corr & $3.74^{* *}$ & $5 \%$ & 3.15 & 4.43 \\
Lrds + lcords & $12.00^{* * *}$ & $1 \%$ & 2.96 & 4.26 \\
Lrds + cim & $9.55^{* * *}$ & $1 \%$ & 2.96 & 4.26 \\
Lrds + lcmrd & $3.55^{* *}$ & $5 \%$ & 2.96 & 4.26 \\
Ltelp & $3.54^{* *}$ & $5 \%$ & 2.96 & 4.26 \\
Ltelp + corr & $3.56^{*}$ & $10 \%$ & 3.15 & 4.43 \\
Ltelp + lcotelp & $6.26^{* * *}$ & $1 \%$ & 2.96 & 4.26 \\
Ltelp + cim & $4.61^{* * *}$ & $1 \%$ & 2.96 & 4.26 \\
Ltelp + lcmtelp & $15.66^{* * *}$ & $5 \%$ & 2.96 & 4.26 \\
\hline
\end{tabular}

Note: ${ }^{*}=10 \%$ significance, ${ }^{* *}=5 \%$ significance, ${ }^{* * *}=1 \%$ significance.

Table 4.2:

\begin{tabular}{lccc}
\hline Variables & Normality Test & Serial Correlation & Test for Heteroscedasticity \\
\hline Equ 1 & $0.386(0.82)$ & $2.99(0.087)$ & $1.34(0.29)$ \\
Equ 2 & $0.50(0.77)$ & $1.74(0.314)$ & $1.23(0.44)$ \\
Equ 3 & $2.49(0.28)$ & $2.76(0.17)$ & $0.81(0.66)$ \\
Equ 4 & $0.74(0.68)$ & $3.51(0.08)$ & $2.03(0.098)$ \\
Equ 5 & $0.70(0.70)$ & $4.57(0.122)$ & $1.67(0.29)$ \\
Equ 6 & $0.58(0.74)$ & $4.22(0.03)$ & $2.95(0.02)$ \\
Equ 7 & $0.13(0.93)$ & $3.6(0.10)$ & $1.61(0.26)$ \\
Equ 8 & $3.23(0.19)$ & $10.4(0.04)$ & $1.11(0.49)$ \\
Equ 9 & $0.18(0.91)$ & $7.00(0.07)$ & $0.67(0.76)$ \\
Equ 10 & $0.039(0.98)$ & $11.04(0.04)$ & $0.62(0.79)$ \\
\hline
\end{tabular}

Table 4.3:

\begin{tabular}{lccccc}
\hline Variables & Equ1 & Equ 2 & Equ 3 & Equ 4 & Equ 5 \\
\hline Lrds & $11.59^{* *}(2.01)$ & $13.1^{* * *}(4.17)$ & $19.71^{* * *}(3.36)$ & $15.85^{*}(1.79)$ & $15.91^{*}(1.79)$ \\
lrds $^{2}$ & $-0.49^{* *}(-2.05)$ & $-0.54^{* * *}(-4.27)$ & $-0.82^{* * *}(-3.41)$ & $0.66^{*}(-1.81)$ & $0.67^{*}(-1.81)$ \\
To & $-0.00-1.14$ & $-0.00^{* *}(-2.22)$ & $0.003(0.66)$ & $0.004(-1.25)$ & $0.004(-1.25)$ \\
Gcf & $-0.02^{*}(-1.78)$ & $-0.01^{* *}(-2.49)$ & $-0.04^{* * *}(-3.15)$ & $-0.02^{* *}(-2.01)$ & $-0.02^{*}(-1.64)$ \\
log(reer) & $-1.25^{* *}(-2.24)$ & $-0.26(-1.14)$ & $-1.20^{* *}(-2.49)$ & $-1.25^{* *}(-2.01)$ & $-1.25^{* *}(-2.00)$ \\
M2 & $0.008^{* * *}(2.75)$ & $0.00^{* * *}(4.87)$ & $0.005^{* * *}(3.74)$ & $0.008^{* * *}(2.54)$ & $0.008^{* *}(2.52)$ \\
Corr & - & $-0.06^{* * *}(-3.16)$ & - & - & - \\
Cim & - & - & - & $0.030(0.471)$ & - \\
Lcords & - & - & $-0.13^{*}(1.89)$ & - & - \\
Lcmrd & - & - & - & - & $0.002(0.48)$ \\
\hline
\end{tabular}

Note: ${ }^{*}=10 \%$ significance, ${ }^{* *}=5 \%$ significance, ${ }^{* * *}=1 \%$ significance.

length of roads and corruption is negatively related to industrial growth. The result can be interpreted as $1 \%$ combined increase in length of roads and corruption index (reduction in corruption) will reduce the industrial growth by $0.13 \%$.

Table 4.4 shows that the coefficient of telephone lines is related positively to industrial growth. How- ever, the isolated impact of telephone lines on industrial growth is nonsignificant. In second equation, in presence of corruption, the coefficient of telephone line is associated positively to industrial growth.

The result of the present study can be explained as in presence of corruption in the economy, $1 \%$ increase in telephone line will improve performance of indus- 
Table 4.4:

\begin{tabular}{lccccc}
\hline variables/equation & Equ 6 & Equ 7 & Equ 8 & Equ 9 & Equ 10 \\
\hline Ltelp & $0.27(1.11)$ & $0.83^{* * *}(3.24)$ & $1.84^{* * *}(15.38)$ & $0.81^{* * *}(4.02)$ & $0.60^{* *}(2.31)$ \\
ltelp & $0.01(-1.42)$ & $-0.030^{* * *}(-3.52)$ & $-0.08^{* * *}(-15.06)$ & $-0.02^{* * *}(-4.4)$ & $-0.02^{* *}(-2.50)$ \\
To & $0.001(0.90)$ & $0.008^{* *}(2.37)$ & $0.63^{* * *}(4.28)$ & $-0.03(-0.36)$ & $-0.002(-1.57)$ \\
Gcf & $0.016^{* * *}(-3.30)$ & $-0.027^{* * *}(-4.41)$ & $-0.03^{* * *}(-14.0)$ & $-0.02^{* *}(-2.65)$ & $-0.03^{* * *}(-4.69)$ \\
log(reer) & $-0.46^{* *}(-2.89)$ & $-0.29^{* *}(-1.41)$ & $-0.06(-0.89)$ & $-0.12(-0.55)$ & $-0.45^{* *}(-2.91)$ \\
M2 & $0.005^{* * *}(4.03)$ & $0.004^{* * *}(5.32)$ & $0.005^{* * *}(8.14)$ & $0.008^{* * *}(8.75)$ & $0.008^{* * *}(7.63)$ \\
Corr & & $-0.05^{* * *}(-3.12)$ & - & - & - \\
Cim & - & - & - & $-0.002(1.35)$ & - \\
Lcotelp & - & - & $-0.49^{* * *}(-3.48)$ & - & - \\
Lcmtelp & - & - & - & - & $0.001(0.32)$ \\
\hline
\end{tabular}

Note: ${ }^{*}=10 \%$ significance, ${ }^{* *}=5 \%$ significance, ${ }^{* * *}=1 \%$ significance.

tries by $0.8 \%$. The third equation result shows that combined impact of telephone lines and corruption is negatively associated to industrial growth. The coefficient can be interpreted as 1 unit combined change will effect industrial growth by $0.1 \%$, inversely. Furthermore, the estimation is preceded by using an alternative proxy of institutional quality that is CIM. Results can be interpreted as, in presence of low contract enforceability, $1 \%$ increase telephone lines will improve industrial growth by $0.6 \%$. The coefficient of CIM shows that CIM is not effecting industrial growth significantly. The interaction term of CIM and telephone is also not significant.

The study has used a quadratic term of both proxies of infrastructure to show the rate at which infrastructure is effecting industrial growth. The results show that similar to findings of Mesike et al. (2010), infrastructure is affecting the industrial growth positively. Industrial growth will increase but at a decreasing rate.

\section{Conclusion and Policy Recom- mendations}

Contribution of industrial growth is an important drive for economic growth of Pakistan. Unfortunately, industrial sector of Pakistan has not been showing a considerable progress, since last two decades. Many researchers, including Ilyas et al. (2010) and Kemal (2006) evaluated the reasons behind under development of industrial growth of Pakistan. According to Imran and Niazi (2011), the reason behind underdevelopment of industrial sector of Pakistan is presence of low quality of infrastructure. According to Méon and Sekkat (2005), institutions are of great importance for industrial sector. They stated that corruption does not hinder the industrial growth rather it makes the transaction easier. Hence, corruption acts as greasing the wheel.

The objective of the study is not only to scrutinize the impact of infrastructure and institutional quality, individually on industrial growth of Pakistan but also the combined impact of infrastructure and institutional quality on industrial growth of Pakistan. The study has touched the unexplored dimension. Therefore, two different proxies for infrastructure and institutional quality are used in every equation. For robust results, every equation is estimated twice, with variables of trade openness, gross capital formation, financial development, and real effective exchange rate.

The results of the present study reject the stated hypothesis. The results show that the combined impact of infrastructure and institutional quality on industrial growth of Pakistan is negative. The infrastructure is related positively to industrial growth. However the quadratic term of infrastructure shows that in relation to infrastructure, industrial growth is increasing but at a decreasing rate. However the weak institutional quality affects the industrial growth positively. A country with weak institutions can face a negative impact of capital formation.

Summarizing the whole study, it can be concluded that better infrastructure and weak institutions affect the industrial growth positively. However, the combined impact of infrastructure and institutional quality on industrial growth is negative.

Keeping in view results of the present study, to achieve considerable and long run industrial growth, following policy recommendations are suggested.

Since infrastructure is affecting industrial growth positively, investment should be made to infrastructure. However, investment in infrastructure should not be at cost of current expenditures; as compensation on current expenditures can deteriorate the industrial growth.

On one hand, weak institutions are promoting industrial growth. On the other hand, presence of corruption hindered the positive impact of gross capital formation. Hence, institutions should be made strong so that pure transactions could be insured. With reference to positive impact of financial development, a little incentive inform of inflation should be provided 
to investors. Increase in inflation should be at decreasing rate. Hence more and more investors will invest to private sector and industrial sector will grow at considerable rate. Anti-corruption laws should be applied strongly, so that illegal industrial activities could be removed. In case of violation of laws, punishment should be same for all.

\section{References}

Arnold, J. M., Javorcik, B., Lipscomb, M., and Mattoo, A. (2015). Services reform and manufacturing performance: Evidence from india. The Economic Journal, 126(590):1-39.

Aschauer, D. A. (1988). The equilibrium approach to fiscal policy. Journal of Money, Credit and Banking, 20(1):41-62.

Aschauer, D. A. (1990). Why is infrastructure. Industry Week.

Bassey, E., Sunday, O., and Okon, E. (2013). The impact of environmental accounting and reporting on organizational performance of selected oil and gas companies in the niger delta region of nigeria. Research Journal of Finance and Accounting, 4(3):57-73.

Chong, A. and Calderon, C. (2000). Causality and feedback between institutional measures and economic growth. Economics $\mathcal{E}$ Politics, 12(1):69-81.

Clarke, G. R. (1995). More evidence on income distribution and growth. Journal of development Economics, 47(2):403427.

Démurger, S. (2001). Infrastructure development and economic growth: an explanation for regional disparities in china? Journal of Comparative economics, 29(1):95-117.

Esfahani, H. S. and Ramirez, M. T. (2003). Institutions, infrastructure, and economic growth. Journal of development Economics, 70(2):443-477.

Fölster, S. and Henrekson, M. (1999). Growth and the public sector: a critique of the critics. European Journal of Political Economy, 15(2):337-358.

Grigorian, D. A. and Martinez, A. (1999). Industrial growth and the quality of institutions: what do (transition) economies have to gain from the rule of law? The World Bank.

Ilyas, M., Ahmad, H. K., Afzal, M., and Mahmood, T. (2010). Determinants of manufacturing value added in pakistan: An application of bounds testing approach to cointegration. Pakistan Economic and Social Review, pages 209-223.

Imran, M. and Niazi, J. (2011). Infrastructure and growth. The Pakistan Development Review, pages 355-364.

Kemal, A. R. (2006). Key issues in industrial growth in pakistan. Lahore Journal of Economics, 11.

Loayza, N. and Wada, T. (2012). Public infrastructure trends and gaps in pakistan.
Mamatzakis, E. (1999). Public infrastructure, private input demand, and economic performance of the greek industry.

Méon, P.-G. and Sekkat, K. (2005). Does corruption grease or sand the wheels of growth? Public choice, 122(1-2):69-97.

Mesike, C., Okoh, R., Inoni, O., et al. (2010). Supply response of rubber farmers in nigeria: an application of vector error correction model. Agricultural Journal, 5(3):146-150.

Meyer, K. E. and Sinani, E. (2009). When and where does foreign direct investment generate positive spillovers? a meta-analysis. Journal of International Business Studies, 40(7):1075-1094.

Narayan, P. K. (2004). Fiji's tourism demand: the ardl approach to cointegration. Tourism Economics, 10(2):193-206.

Nawatmi, S., Nusantara, A., and Isnowati, S. (2016). The relationship of corruption and economic growth. Proceeding ICOBAME.

North, D. C. (1993). Institutions and credible commitment. Journal of Institutional and Theoretical Economics (JITE)/Zeitschrift für die gesamte Staatswissenschaft, pages 11-23.

Okoh, A. S. and Ebi, B. O. (2013). Infrastructure investment, institutional quality, and economic growth in nigeria: An interactive approach. European Journal of Humanities and Social Sciences, 26(1).

Pesaran, M. H., Shin, Y., and Smith, R. J. (2001). Bounds testing approaches to the analysis of level relationships. Journal of applied econometrics, 16(3):289-326.

Power, J. H. (1963). Industrialization in pakistan: A case of frustrated take-off? The Pakistan Development Review, 3(2):191-207.

Redek, T. and Sušjan, A. (2005). The impact of institutions on economic growth: the case of transition economies. Journal of Economic Issues, 39(4):995-1027.

Rodrik, D., Subramanian, A., and Trebbi, F. (2004). Institutions rule: the primacy of institutions over geography and integration in economic development. Journal of economic growth, 9(2):131-165.

Seidman, G. W. (1994). Manufacturing militance: workers' movements in Brazil and South Africa, 1970-1985. Univ of California Press.

Shah, A. (1992). Dynamics of public infrastructure, industrial productivity and profitability. The review of economics and statistics, pages $28-36$.

Thompson, T. and Shah, A. (2005). Transparency internationals corruption perceptions index: Whose perceptions are they anyway. Retrieved May, 14:2013.

Valeriani, E., Peluso, S., et al. (2011). The impact of institutional quality on economic growth and development: An empirical study. Journal of Knowledge Management, Economics and Information Technology, 1(6):1-25. 